\title{
Assessment of knowledge on anemia and the effectiveness of lemon juice in improving Hemoglobin level among Adolescent.
}

\author{
Mrs. Carolin.P ${ }^{* *}$ Dr. Kamalam. S \&*** Mrs. Aruna Devi.
}

\begin{abstract}
:
Objectives: To find out the level of knowledge regarding anemia on adolescent girls and to assess the effectiveness of lemon juice in improving Hemoglobin level. Method: Experimental (pretest posttest control group) design. Result: In this the mean pre test Hb level for the experimental and the control is 8.87 and 8.0. The mean post $\mathrm{Hb}$ level for the experimental and the control is 9.88 and 8.09 respectively. That is ' $p$ ' value is $0.000^{* * *}$ which is less than 0.001 so highly significant. Conclusion: The consumption of the lemon juice has significant effectiveness in improving the haemoglobin level of the samples.
\end{abstract}

Key words : Anemia, Lemon Juice \& Hemoglobin Level

\section{INTRODUCTION}

Anemia is the major nutritional problem in India and many other developing countries. India is facing a grave public health problem, with the prevalence of anemia in India being $>40 \%$. It is reported that $65-75 \%$ of the population in India suffering from anemia.

As today's adolescent girls are the future mothers and since anemia causes severe consequence on the health of the future generation, it is better to treat the anemia during adolescent period itself. It is seen that anemia affects the overall nutritional status of adolescent females.

\section{Objectives:}

- To find out the level of knowledge regarding anemia on adolescent girls.

- To find out the level of Hemoglobin among adolescent girls.
- To assess the prevalence of anemia among adolescent girls.

- To determine the effectiveness of lemon juice on Hemoglobin level among adolescent girls.

- To associate the Hemoglobin level of the experimental and control group with the selected demographic variables.

\section{METHODOLOGY:}

Research approach used for the study was Quantitative Research Approach and the Research design was Experimental Research design. 60 adolescent students studying B.Sc Nursing $1^{\text {st }}$ year in Kasturba Gandhi Nursing College at Puducherry, who met the inclusion and exclusion criteria's were selected. Simple Random Sampling Technique was used to select the samples. Blood hemoglobin level was assessed and per day $200 \mathrm{ml}$ of lemon juice was given a period of 30 days for 30 samples in experimental groups. 
Blood hemoglobin level was reassessed after 30 days of lemon juice administration. For control group only blood Hemoglobin level was assessed. The data were analysed by using descriptive and inferential statistics like frequency, percentage, mean, standard deviation, paired T-Test and Chi-Square test.

\section{RESULTS:}

Distribution of assessment of hemoglobin levels and prevalence of anemia among adolescent girl

$$
\mathrm{N}=60
$$

\begin{tabular}{|c|c|c|c|c|}
\hline Group & Mild & $\begin{array}{c}\mathbf{P} \\
\mathbf{( \% )}\end{array}$ & $\begin{array}{c}\text { Mod- } \\
\text { erate }\end{array}$ & $\begin{array}{c}\mathbf{P} \\
\mathbf{( \% )}\end{array}$ \\
\hline Control & 21 & $70 \%$ & 9 & $30 \%$ \\
\hline $\begin{array}{l}\text { Experi- } \\
\text { mental }\end{array}$ & 2 & $7 \%$ & 28 & $93 \%$ \\
\hline
\end{tabular}

It shows that $93 \%$ of the adolescent girls in the experimental group had moderate anemia, $7 \%$ of the students had mild anemia, $70 \%$ of the students in the control group had moderate anemia and $30 \%$ of the student had mild anemia.

Prevalence of anemia among Experimental and Control group

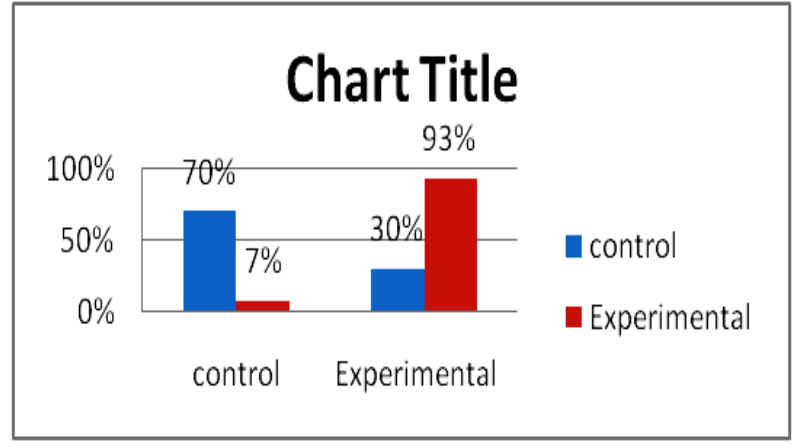

Comparison of Hemoglobin level between the experimental and the control group

\begin{tabular}{|c|c|c|c|c|c|}
\hline Groups & Pre-test $\mathrm{Hb}$ & Post-test $\mathrm{Hb}$ & $S . D$ & 't'value & 'p'value \\
\hline $\begin{array}{l}\text { Experimental } \\
\text { group }\end{array}$ & 8.87 & 9.88 & 0.59 & \multirow{2}{*}{-1.000} & \multirow{2}{*}{$\begin{array}{c}P=0.000^{* * *} \\
H S\end{array}$} \\
\hline Control group & 8.0 & 8.09 & 0.53 & & \\
\hline
\end{tabular}

${ }^{* * *} p<0.001$, HS- Highly Significant

Percentage and frequency distribution of knowledge on anemia

\begin{tabular}{|c|c|}
\hline LEVEL OF KNOWLEDGE & PERCENTAGE \\
\hline No knowledge & $51 \%$ \\
\hline Moderate knowledge & $47 \%$ \\
\hline Adequate knowledge & $2 \%$ \\
\hline
\end{tabular}


The study findings revealed that the mean haemoglobin level between the experimental and the control group. In this the mean pre test $\mathrm{Hb}$ level for the experimental and the control is 8.87 and 8.0. The mean post $\mathrm{Hb}$ level for the experimental and the control is 9.88 and 8.09 rescepectively. Hence it was found that the consumption of the lemon juice has significant effectiveness in improving the haemoglobin level of the samples. That is ' $\mathrm{p}$ ' value is $0.000^{* * *}$ which is less than 0.001 so highly significant.

\section{RECOMMENDATIONS:}

- The study can be replicated with a larger sample.

- The same study can be done as a comparative study between the urban and rural adolescent girls.

- The similar study can be conducted with an intervention for 60-90 days.

- The similar study can be conducted for women in reproductive age groups.

- The study can be conducted with different combinations of iron supplements to improve the hemoglobin level.

\section{CONCLUSION:}

Vitamin C rich foods like lemon juice will aid in good absorption, so that there will be a significant improvement in the level of hemoglobin during post test in the experimental group when compared the control group. Here education plays a major role. As nurses its our responsibility to implement educational programmes which are necessary to improve the knowledge of adolescent girls regarding Vitamin C rich foods for the better iron absorption.

\section{REFERENCES:}

1. Basavanthappa BT.(2006). Text book of Medical and Surgical Nursing. $1^{\text {st }}$ edition. New Delhi: Jaypee Brothers Medical Publishers (P) ltd.

2. Black M J (2004) Hawks. Medical Surgical Nursing: clinical management for positive outcomes. $7^{\text {thed. New }}$ Delhi: Elseiver.

3. Dr. Swaminathan.(2008). Advansed text book on food and hygiene. Volume1. Bangalore. Published by Bappco Publisher. Page No. 392-94.

4. Lewis et al (2011). Medical surgical Nursing. 11 editions. New Delhi: Mosby Pubilcation.

\section{International PeEr Review Members}

\author{
Mr. Allan Seraj \\ Senior Practice Educator in ICU \\ RoyalBrompton\&Harefield Hospital \\ NHS Trust, UK
}

\author{
Dr. Rachelle (Shelly) J. \\ Lancaster \\ Associate Professor of Nursing \\ Oshkosh College of Nursing \\ University of Wisconsin \\ Oshkosh Wisconsin, USA.
}

